\title{
Electrochemical deposition of platinum nanoparticles on different carbon supports and conducting polymers.
}

\author{
Sonia Domínguez-Domínguez ${ }^{a}$, Joaquín Arias-Pardilla ${ }^{b}$, Ángel Berenguer-Murcia ${ }^{a}$, \\ Emilia Morallón $^{b, 1}$, Diego Cazorla-Amorós ${ }^{a}$ \\ ${ }^{a}$ Dpto. Química Inorgánica and Instituto Universitario de Materiales, Facultad de \\ Ciencias. Universidad de Alicante. Ap. 99, San Vicente del Raspeig. 03080.- Alicante. \\ Spain \\ ${ }^{\text {b }}$ Dpto. Química Física and Instituto Universitario de Materiales. Universidad de \\ Alicante. Ap. 99, San Vicente del Raspeig. 03080.- Alicante. Spain
}

\begin{abstract}
Electrodeposition of $\mathrm{Pt}$ nanoparticles under potentiostatic conditions was performed on several types of carbon electrode supports: a commercial macroporous carbon (which can be considered as a three-dimensional electrode), glassy carbon, graphite and conducting polymers (polyaniline and poly-o-aminophenol). The platinum nanoparticles were obtained by different Potential Step Deposition (PSD) methods in $5 \mathrm{mM} \mathrm{H} \mathrm{PtCl}_{6}+0.5 \mathrm{M} \mathrm{H}_{2} \mathrm{SO}_{4}$ aqueous solutions. The effect of the final potential, time and number of steps on the quantity, distribution and size of the platinum nanoparticles deposited on the supports was analysed. The mechanism of the electrochemical deposition of platinum was studied by applying theoretical models found in the literature, being the progressive nucleation mechanism the most consistent with our results. In addition, the chemical state and morphology of the electrodeposited materials

\footnotetext{
1 Corresponding author. Tel: +34 96590 9590; fax: +34 96590 3537. E-mail adress: $\underline{\text { morallon@ua.es }}$ (Emilia Morallón).
} 
were determined by means of SEM, TEM, and XPS. It has been observed by Impedance Spectroscopy that the presence of a thin layer of conducting polymer increases the resistivity of the electrode. As consequence, the platinum particle increases and the amount of platinum deposited is lower than in absence of polymer.

Keywords: Carbon supports; Conducting polymers; Electrodeposition; Platinum; Electrocatalysis. 


\section{1.- INTRODUCTION}

Several procedures have been employed to prepare Pt-supported nanoparticles on different supports, including wet impregnation [1, 2], microwave irradiation [3], microemulsion [4, 5], polyol process [6, 7], micro-wave assisted polyol process [8] or twostep spray pyrolysis [9]. On the other hand, electrochemical deposition is an efficient method to prepare metal particles. It is widely used employing different strategies/methodologies, such as cyclic voltammetry [10, 11], potential step deposition $[12,13,14,15]$ and double-pulse $[16,17,18]$. Among these, potential step deposition (PSD) provides us a tool to control the amount of metal that is deposited, the number of metallic sites and their size to a fairly small scale.

Carbon materials are of special interest in the field of electrode materials due to their outstanding properties, such as their tuneable shape, size and porosity, chemical stability, corrosion resistance, low cost, good thermal resistance and electrical conductivity $[19,20,21]$. So, the combination of all these characteristics has promoted the use of these compounds as electrode supports. Our research group already has experience in the deposition of noble metals by electrochemical methods on different carbon supports $[22,23,24]$.

Conducting polymers are considered to be useful supports for the inmobilization of the dispersed noble metal catalyst because the agglomeration is prevented. Porous structure and high surface area of many conducting polymers favour their use as supporting material for the development of new electrocatalytic materials. Because of a relative high electric conductivity of some polymers, it is possible to transfer the 
electrons through polymer chains between the electrode and dispersed metal particles, where the electrocatalytic reaction occurs $[25,26]$.

Then, in this work, the influences of the different experimental variables during the Pt electrochemical deposition by potential step deposition on the different supports is analysed. The effect of the presence of a thin layer of conducting polymers is also analysed. The amount of deposited particles and their size is controlled by the selection of the potential step deposition conditions. The outcome is an electrode homogeneously covered with metallic nuclei of a nanometer scale size and showing a good dispersion. The prepared composites have been tested for the electro-oxidation of methanol.

\section{2.- EXPERIMENTAL}

\subsection{Preparation of the supports}

Different carbon materials have been used to prepare the working electrodes for the platinum electrodeposition: macroporous carbon disc, glassy carbon and graphite. The macroporous carbon discs, which were cut from a macroporous carbon sheet (thickness $=0.3 \mathrm{~mm}$, mean pore size $0.7 \mu \mathrm{m}$, exposed geometric area $2.91 \mathrm{~cm}^{2}$ ) provided by Poco Graphite (DFP-1) were washed in an ultrasonic bath with distilled water at room temperature for 30 minutes. The graphite (Ellor +35$)$ and glassy carbon (CV25) were rods of $0.3 \mathrm{~cm}$ in diameter from Carbone Lorraine.

In all cases, the materials were first treated with sandpaper, and were then polished with two different diamond suspensions (particle sizes 1 and $0.25 \mu \mathrm{m}$, respectively), and finally washed in an ultrasonic bath with ultrapure water for 5 minutes.

The conducting polymers layers were electrochemically deposited on glassy carbon by cyclic voltammetry between 0.06 and $1.10 \mathrm{~V}$ from a $0.1 \mathrm{M}$ aniline or o- 
aminofenol in a supporting electrolyte of $0.5 \mathrm{M} \mathrm{H}_{2} \mathrm{SO}_{4}$ at a scan rate of $50 \mathrm{mV} \mathrm{s}^{-1}$. Although different expressions can be found for film thickness determination in literature, an EQCM experiment [27] was used to calculate film thickness from polymer peak voltammetric charge.

\subsection{Platinum electrodeposition}

The electrodeposition of platinum particles on the different electrodes was performed in a conventional electrochemical cell of three electrodes at room temperature. All the reagents used were of analytical grade, and these and other materials were used without further purification. An EG\&G potentiostat/galvanostat model 263A controlled by the program POWER SUITE was employed, so the values of current and time were monitored by a computer. For all the experiments the counterelectrode was a platinum wire. The reference electrode was a reversible hydrogen electrode (RHE), immersed in $0.5 \mathrm{M} \mathrm{H}_{2} \mathrm{SO}_{4}$ solution, which was connected to the working electrode compartment by a Luggin capillary.

All solutions were prepared with high-purity water (resistivity $=18 \mathrm{M} \Omega \cdot \mathrm{cm}$ ) which was obtained from an Elga Labwater Purelab Ultra system. The solutions used were $0.5 \mathrm{M} \mathrm{H}_{2} \mathrm{SO}_{4}$ (Merck, suprapur), $5 \mathrm{mM} \mathrm{H}_{2} \mathrm{PtCl}_{6}$ (starting material $\mathrm{H}_{2} \mathrm{PtCl}_{6} \cdot 6 \mathrm{H}_{2} \mathrm{O}$, SigmaAldrich) $+0.5 \mathrm{M} \mathrm{H}_{2} \mathrm{SO}_{4}$, and $0.1 \mathrm{M} \mathrm{CH} 3 \mathrm{OH}$ (Merck) $+0.5 \mathrm{M} \mathrm{H}_{2} \mathrm{SO}_{4}$ solution. All solutions were saturated with nitrogen before their use and this inert atmosphere was maintained during the experiments.

The platinum particles were electrochemically deposited from a $5 \mathrm{mM} \mathrm{H}_{2} \mathrm{PtCl}_{6}+$ $0.5 \mathrm{M} \mathrm{H}_{2} \mathrm{SO}_{4}$ solution under potentiostatic conditions. Thus, in order to study the influence of different parameters on the electrodeposition of platinum, four different experimental procedures were used: 
Procedure (1): one step from an initial potential $(0.80 \mathrm{~V}$, where no deposition of platinum occurs) to different final potentials $(0.20,0.15,0.10,0.05 \mathrm{~V}$ in which the platinum is deposited) for different times (from 0.1 to $60 \mathrm{~s}$ ).

Procedure (2): several consecutive steps from an initial potential $(0.80 \mathrm{~V})$ to a final potential $(0.15 \mathrm{~V})$ for different times, being the total time the same as in procedure (1).

Procedure (3): one step from an initial potential $(0.80 \mathrm{~V})$ to an intermediate potential $(-0.35,-0.25,-0.15,0.0 \mathrm{~V})$ for $1 \mathrm{~s}$, and immediately to several final potentials $(0.20,0.15,0.10,0.05 \mathrm{~V})$ during $6 \mathrm{~s}$.

Procedure (4): multiple consecutive steps of short time (5 ms) from an initial potential $(0.80 \mathrm{~V})$ to a final potential $(0.00$ or $-0.15 \mathrm{~V})$ for $5 \mathrm{~ms}$ and being the total time $5 \mathrm{~s}$.

The electrochemical properties of the prepared Pt-supported electrodes were tested in methanol oxidation, which was measured in $0.1 \mathrm{M} \mathrm{CH}_{3} \mathrm{OH}+0.5 \mathrm{M} \mathrm{H}_{2} \mathrm{SO}_{4}$ solution by cyclic voltammetry over the potential range of 0.06 to $1.0 \mathrm{~V}$ with a scan rate of 10 $\mathrm{mV} \cdot \mathrm{s}^{-1}$

\subsection{Characterisation of the Pt-supported electrodes}

X-Ray Photoelectron spectra (XPS) were recorded using a VG-Microtech Multilab electron spectrometer to investigate the oxidation state of the electrochemically deposited platinum. The prepared $\mathrm{Pt} / \mathrm{C}$ electrodes were not reduced in any way before the XPS analysis, although they were exposed to air after their synthesis. The source employed was the $\mathrm{MgKa}\left(h ?=1253.6 \mathrm{eV}, 1 \mathrm{eV}=1.603 \times 10^{-19} \mathrm{~J}\right)$ radiation of twin anode in the constant analyser energy mode, and the pressure of the analysis chamber was 
maintained below $5 \times 10^{-10}$ mbar. The binding energy was adjusted by setting the $\mathrm{C} 1 \mathrm{~s}$ transition at $284.6 \mathrm{eV}$ with $\pm 0.2 \mathrm{eV}$ accuracy. The intensities of the peaks were estimated by determining the integral of each peak after subtraction of an S-shaped background and fitting the experimental peak to Lorentzian/Gaussian lines $(70 \% \mathrm{~L} / 30 \% \mathrm{G})$.

The active surface area of electrodeposited Pt was measured by comparing the charge corresponding to the adsorption/desorption processes at Pt sites between $0.05 \mathrm{~V}$ and $0.45 \mathrm{~V}$ of the cyclic voltammograms $(\mathrm{CVs})$ of the synthesized electrodes in $0.5 \mathrm{M}$ $\mathrm{H}_{2} \mathrm{SO}_{4}$ aqueous solutions, before and after platinum deposition.

The morphological characterisation of the surface of the platinum/carbon electrodes was studied by Scanning Electron Microscopy (SEM) using a JEOL JSM840 equipment.

Platinum particles were also characterized by Transmission Electron Microscopy (TEM) using a JEOL JEM-2010 operating at $200 \mathrm{kV}$ with a structural spatial resolution of $0.5 \mathrm{~nm}$, to observe the size of the smallest platinum particles that could not be detected with SEM images. For the observation of the samples, these were scraped and the collected powder dispersed into ethanol, then the suspension was put onto a $3 \mathrm{~mm}$ diameter copper grid covered with carbon film, and finally the solvent was evaporated in air.

Impedance measurements were obtained using Princeton Applied Research FRD100 frequency response analyzer and data collection using PowerSine software. The frequency range of the impedance measurements was $100 \mathrm{kHz}$ to $1 \mathrm{~Hz}$. The nominal applied potential was $0.80 \mathrm{~V}$ with a peak-to-peak voltage of $10 \mathrm{mV}$.

\section{3.- RESULTS AND DISCUSSION}




\subsection{Preparation of Pt-supported electrodes}

Figure 1a shows the chronoamperometric experiments for three platinum deposition experiments by Procedure 1 using a macroporous carbon disc. These current vs time transients are common responses for electrochemical deposition [28]. Three different zones are distinguishable, being these different stages very similar to those reported by Montilla et al. on the deposition of platinum on synthetic boron-doped diamond surfaces [24]: the first one corresponds to the double-layer charging current and the initiation of the nucleation process. In the second zone the current increases due to the growth of either independent nuclei alone or independent nuclei and simultaneous increase in number of nuclei. At this point, the current corresponds to the deposition current without overlapping effect. In the third zone, there are two opposite effects: growth of independent nuclei and overlap, reaching a maximum of the current and then the current decreases.

In this Figure 1a, the electrical charge in the deposition process decreases with the increase in the potential (from 0.05 to $0.15 \mathrm{~V}$ ).

Table 1 contains the amount of platinum deposited during two methods according to Procedure 1 and Procedure 2. The values are obtained by graphical integration of the electrical charge consumed during the deposition process $Q_{P t}\left(\mathrm{C} \mathrm{cm}^{-2}\right)$, assuming a $100 \%$ of current efficiency, discarding partial reductions of $\mathrm{Pt}^{4+}$, hydrogen evolution at the electrodeposited Pt or the double layer charging, and assuming that this value is only due to the Faradaic reaction (1):

$$
\mathrm{PtCl}_{6}^{2-}+4 e^{-} \rightarrow \mathrm{Pt}+6 \mathrm{Cl}^{-}
$$

So, the quantity of deposited $\mathrm{Pt}\left(m_{P t}\right)$ is obtained from the next equation (2): 
$m_{P t}=\frac{Q_{P t} \cdot M}{4 F}$

where $M=195.09 \mathrm{~g} \cdot \mathrm{mol}^{-1}$ is the atomic weight of $\mathrm{Pt}$, and $F=96485.309 \mathrm{C} \cdot \mathrm{mol}^{-1}$ is the Faraday constant.

It can be observed that the amount of platinum deposited increases with increasing the step time. This rise in the aforementioned value is also achieved with the application of Procedure 2, that is, without changing the initial or final potential, but by replacing a large step for several short steps with the same final duration, as is observed in Table 1 . This might be better explained analysing the type of growth as shown later.

Fig. 1b shows the chronoamperometric curves for a Potential Step Deposition experiment of a double step (Procedure 3) with samples of glassy carbon at different intermediate potentials but maintaining the final potential. During the first step together the deposition of platinum, the hydrogen evolution reaction also occurs and produces the negative current. It could be observed that the application of a negative potential in the first step increases the amount of electrodeposited platinum (Table 2), although, at the same time, the charge of the hydrogen evolution is also higher producing a higher imprecision in the determination of the amount of platinum deposited.

The chronoamperometric curves of the Fig. 1c correspond to a multiple steps of Potential Step Deposition (Procedure 4) with samples of glassy carbon. These curves have a very similar shape compared with those of the single step, and the main difference is attributed to the continuous change in the potential. A secondary nucleation process can also be observed.

From the chronoamperograms, it is possible to obtain information on the mechanism through which both nucleation and growth processes occur. Other authors [29, 30] have established mathematical current-time relationships for determining the kinetics of the nucleation mechanism and the geometry of the growing particles. 
Regarding nucleation, there may be instantaneous nucleation, in which there are a small number of active sites where the nuclei are created at the same time and have a slow growth, or progressive nucleation, in which there are many active sites, the nuclei have a fast growth and new nuclei are continuously formed during the deposition process. In the latter, for ascertaining the geometry of the growing particles, either $2 \mathrm{D}$ islands or $3 \mathrm{D}$ clusters may be formed.

The models for the different types of nucleation and growth mechanisms are given by the equations (3) 2D instantaneous, (4) 2D progressive, (5) 3D instantaneous and (6) 3D progressive:

$$
\begin{aligned}
& \frac{I}{I_{m}}=\frac{t}{t_{m}} \exp \left[-\frac{1}{2}\left(\frac{t^{2}-t_{m}^{2}}{t_{m}^{2}}\right)\right] \\
& \frac{I}{I_{m}}=\left(\frac{t}{t_{m}}\right)^{2} \exp \left[-\frac{2}{3}\left(\frac{t^{3}-t_{m}^{3}}{t_{m}^{3}}\right)\right] \\
& \left(\frac{I}{I_{m}}\right)^{2}=\frac{3.8181}{t / t_{m}}\left\{1-\exp \left[-1.2564\left(\frac{t}{t_{m}}\right)\right]\right\}^{2} \\
& \left(\frac{I}{I_{m}}\right)^{2}=\frac{1.2254}{t / t_{m}}\left\{1-\exp \left[-2.3367\left(\frac{t}{t_{m}}\right)^{2}\right]\right\}^{2}
\end{aligned}
$$

where $I_{m}$ and $t_{m}$ are the values of current and time of the maximum peak.

With the aim of characterizing the electrodeposition process, the experimental values for platinum electrodeposits on the macroporous carbon were analyzed. Thus, the results corresponding to a PSD process of one step from an initial potential of $0.80 \mathrm{~V}$ to a final potential of $0.05 \mathrm{~V}$ for $15 \mathrm{~s}$ (procedure 1), together with the theoretical models for the two types of nucleation and growth mechanisms are shown in Fig. 2. It can be observed that the experimental curve fits better to the $3 \mathrm{D}$ progressive nucleation mechanism. Thus, the deposited particles are spherical, distributed throughout the entire 
electrode surface and have a rather broad particle size distribution. Even though only one example is showed, this conclusion is also observed in the cases of graphite and glassy carbon. These results are in agreement with other works [24, 31] for similar electrochemical deposition of platinum on other electrodes. The type of nucleation process of the electrodeposition could be controlled by the concentration of metal precursor, like other authors have previously observed in graphite [31]. In our case the concentration of $5 \mathrm{mM} \mathrm{H}_{2} \mathrm{PtCl}_{6}$ was maintained in all the experiences.

In the case of $\mathrm{Pt}$ deposition on conducting polymers, the cronoamperometric curves obtained are very similar, however no Pt deposition was observed using procedure 4. Figure 3 shows the comparison between experimental data and 3D nucleation models. As it can be observed, the data fits with a 3D progressive nucleation it the case of Pt depostion over a PANI film $(500 \mathrm{~nm})$, but the fit is not good for POAP. This behaviour was previously observed in Ag deposition over POAP modified electrodes [32] when high overpotential was used for the deposition. This fact points out a difference in the deposition mechanism, due to the different polymers used.

\subsection{Characterisation of Pt-supported electrodes}

The chemical oxidation states of the electrodeposited Pt were determined by XPS. As shown in Fig. 4, the Pt $4 \mathrm{f}$ peak shows two overlapping peaks at the binding energy values of about 71.1 and $74.3 \mathrm{eV}$, these values correspond to $\mathrm{Pt} 4 \mathrm{f}_{7 / 2}$ and $\mathrm{Pt} 4 \mathrm{f}_{5 / 2}$ peaks, respectively, that are very close to the binding energies of metallic $\mathrm{Pt}$, whereas $\mathrm{Pt}^{+2}$ and $\mathrm{Pt}^{+4}$ would exhibit much higher binding energies [33]. These results demonstrate that platinum is essentially deposited as metallic platinum. 
The active surface area $\left(\mathrm{S}_{\mathrm{Pt}}: \mathrm{m}^{2} \mathrm{~g}^{-1}\right)$ of the Pt-supported electrodes could be evaluated from the electrical charge measured in the characteristic adsorptiondesorption processes on $\mathrm{Pt}$, using the voltammogram in $0.5 \mathrm{M} \mathrm{H}_{2} \mathrm{SO}_{4}$ solution, before and after the platinum electrodeposition. Fig. 5 shows the cyclic voltammograms of the glassy carbon, before and after the platinum deposition. The electrochemically surface area is estimated assuming that $1 \mathrm{~cm}^{2}$ of smooth $\mathrm{Pt}$ requires $210 \mu \mathrm{C}$ [34] for an adsorption process of one electron per Pt site.

The mean diameter $(\mathrm{d}, \mathrm{nm})$ of the $\mathrm{Pt}$ particles is calculated from the specific surface area assuming that this value is the ratio between the area and the weight of one particle and a spherical shape of the particles (7):

$d=\frac{6000}{\rho_{P t} \times S_{P t}}$

where $?_{\mathrm{Pt}}$ is the platinum specific density $\left(21.4 \mathrm{~g} \cdot \mathrm{cm}^{-3}\right)$.

Table 2 summarizes the characteristics of different platinum electrodeposits on the macroporous carbon. It can be observed that the platinum particle diameter varies between 9 and $30 \mathrm{~nm}$. These results are similar for the glassy carbon and the graphite electrodes, however they are not shown. Particle size depends on the time, the number of steps and of the potentials used in the PSD. However, interestingly, the methods in which an intermediate pulse at negative potentials is applied (procedures 3 or 4), produce smaller Pt particle size. These methods base on a first short nucleation pulse at negative potentials, where the nuclei formation initiates, followed by a second longer pulse at positive potentials, where the nuclei grow; however, this second potential must be positive enough to inhibit the formation of new nuclei. This permits to generate more nuclei of platinum with controlled size distribution than in the rest of the procedures.

In order to verify the particle size of the deposited platinum, SEM analyses has been done for the $\mathrm{Pt} / \mathrm{C}$ electrodes in which the lower particle size is obtained in Table 2. 
SEM micrographs of platinum deposited on the three carbon supports under the same conditions are shown in Fig. 6. In general, the particles exhibit uniform size and spherical shape and appear homogeneously distributed over all the support surface. In the case showed in Fig. 6 (Procedure 3: one step from $0.80 \mathrm{~V}$ to an intermediate potential of $-0.15 \mathrm{~V}$ for $1 \mathrm{~s}$, and immediately, a second step to $0.10 \mathrm{~V}$ for $6 \mathrm{~s}$ ), the particles are approximately of $36 \mathrm{~nm}$ in diameter in the three types of carbon electrodes.

The observed platinum particle size by SEM images is rather bigger than the calculated diameters by cyclic voltammetry. This may be due to the impossibility of observing small particles by SEM or because the observed particles are constituted by aggregation of smaller particles; for this reason TEM observations were done with the $\mathrm{Pt} /$ macroporous carbon obtained according to procedure 3 in order to characterise the prepared electrodes. As it can be observed in Fig. 7, the electrodeposited platinum particles are of different size and can reach diameters as small as 3-5 $\mathrm{nm}$ see inset in the images. Interestingly, the particles of about $40 \mathrm{~nm}$ are constituted by agglomerates of small particles of about 3-5 nm (see the lower image in Fig. 6). Thus, the particle size obtained from the cyclic voltammetry agrees with the microscopy observations.

The same behaviour was observed in the Pt/conducting polymer electrodes, the platinum particle size by SEM images is bigger that the calculated diameter by cyclic voltammetry. The obtained values are slightly bigger than those obtained without polymer film, and very similar using both PANI and POAP (Table 3).

\subsection{Electrocatalytic test of P-supported electrodes in the electro-oxidation of} methanol 
A series of cyclic voltammograms tests of the Pt/carbon electrodes in a $0.1 \mathrm{M}$ $\mathrm{CH}_{3} \mathrm{OH}+0.5 \mathrm{M} \mathrm{H} \mathrm{SO}_{4}$ solution were carried out for characterizing the behaviour of the synthesized electrodes in methanol oxidation. Fig. 8 shows the cyclic voltammograms obtained during the third cycle for the best Pt-supported electrodes obtained. The oxidation peaks of methanol are observed at about 0.83 and $0.76 \mathrm{~V}$ being the starting potential of methanol oxidation at approximately $0.49 \mathrm{~V}$ for glassy carbon electrode and $0.55 \mathrm{~V}$ for the macroporous carbon and graphite electrodes, and similar values in the case of using conducting polymers as supports. The catalytic activity of the prepared catalysts is defined as the maximum current obtained during the third cycle of the methanol oxidation per weight of Pt.

Table 1 and Table 2 show the values of catalytic activity towards methanol oxidation for all procedures with a macroporous carbon (similar behaviour is obtained with graphite and glassy carbon samples). It can be observed that a multiple step deposition procedure produces the best catalytic activity for methanol oxidation. Table 4 summarizes the results for the three types of Pt/carbon obtained in the same conditions (Procedure 4). The improvement of the Multiple Step Deposition method compared to the other three procedures was also observed by other authors [35].

The best conditions for the deposition for each electrode were analysed from the involved parameters, that is, potentials and time of the steps, and electrocatalytic activity. Table 5 compares the catalytic activity obtained for catalysts prepared with the different supports at the best conditions for each sample.

The difference in the activity values in the case the carbon supports could not be attributed to the different size of electrodeposited particles because they are very similar in all cases (around $10 \mathrm{~nm}$ ). It can be observed that the catalytic activity obtained with the Pt/macroporous carbon electrode is about 1.7 times higher than the other electrodes. 
This greater performance of the macroporous carbon support could be associated to its characteristic porosity, allowing the use of all the surface of the support as a threedimensional electrode. The obtained catalytic activities are higher or similar than those previously reported at similar conditions $[16,24,36]$. In the case of Pt/conducting polymer the activity values are lower, but there are no difference between PANI and POAP. In our conditions the introduction of a polymer thin film in the electrode does not increase the catalytic activity of the studied reaction.

Fig. 9 plots the catalytic activity versus the particle size of the platinum-supported electrodes obtained by the four procedures. The catalytic activity towards methanol oxidation increases as the platinum particle size decreases determining the optimal platinum diameters between 2 and $10 \mathrm{~nm}$, as other authors previously observed it. Then, particles with smaller or bigger diameters show less activity for methanol oxidation [37, 38]. In the case of Pt/glassy carbon electrodes an increase in the catalytic activity is obtained for a Pt particle size of around $20 \mathrm{~nm}$. This behaviour suggests that the $\mathrm{Pt}$ particle structure is different when the growth occurs on the glassy carbon compared with the other supports. It should be noted that both the graphite and the macroporous carbon have similar structure (the macroporous carbon is prepared from graphite particle agglomeration), which is distinct to that of glassy carbon.

Fig. 10 shows the impedance data obtained with different electrodes during methanol oxidation at $0.8 \mathrm{~V}$. As can be observed that an increase of conducting polymer thickness from 130 to $500 \mathrm{~nm}$ suppose and increase of the charge transfer resistance [39], being in the case of smaller thickness very similar to the one without polymer. Therefore, the increase of thickness of the conducting polymer film seems to reduce to the speed of transference of charge in the interphase carbon/platinum supported|solution in our conditions. 


\section{4.- CONCLUSIONS}

Pt particles with high dispersion were electrodeposited by different potential step deposition methods on different supports: carbon (macroporous carbon, glassy carbon and graphite) and conducting polymers (polyaniline and poly-o-aminophenol). The particle size of platinum could be adjusted by selection of the conditions of the potential step deposition (PSD), which are the number of steps, time of the step and the initial and final potentials. Controlling these parameters, the average size of the platinum particles varies between 9 and $30 \mathrm{~nm}$. The PSD of multiple pulses has been found to be the most suitable method in order to obtain small and uniform platinum particles deposited on the different supports. The electrocatalytic activity of Pt/carbon electrodes has been investigated in a $0.1 \mathrm{M} \mathrm{MeOH}+0.5 \mathrm{M} \mathrm{H}_{\mathbf{L}} \mathrm{SO}_{4}$ solution by cyclic voltammetry from $0.06 \mathrm{~V}$ to $1.0 \mathrm{~V}$ with a scan rate of $10 \mathrm{mV} \mathrm{s}^{-1}$. The highest catalytic activity of the macroporous carbon with respect to the other carbon electrodes may be associated to the three-dimensional character that can be of interest for an application point of view. The introduction of a thin film of PANI or POAP suppose a slightly bigger platinum particle size, decreasing catalytic activity of methanol oxidation. Impedance measurements during methanol oxidation with Pt supported on conducting polymers shown that charge transfer resistance increases with polymer thickness.

\section{ACKNOWLEDGEMENTS}


The authors would like to thank Spanish Ministerio de Educación y Ciencia (Projects CTQ2006-08958/PPQ and MAT2004-1479) and the EU (FEDER) for financial support. 


\section{TABLES}

Table 1. Amount of platinum deposited on macroporous carbon by PSD from an initial potential of $0.80 \mathrm{~V}$ to a final potential of $0.15 \mathrm{~V}$ under different conditions (assuming 100\% current efficiency for Pt deposition and referred to the geometric area of the carbon disc), particle size and catalytic activity towards methanol oxidation.

\begin{tabular}{|c|c|c|c|c|c|c|}
\hline $\begin{array}{c}\text { PSD } \\
\text { Method }\end{array}$ & $\begin{array}{c}\text { Number of } \\
\text { steps }\end{array}$ & $\begin{array}{c}\text { Time of } \\
\text { steps }(s)\end{array}$ & $\begin{array}{c}m_{P t} \\
\left(\mu \mathrm{g} / \mathrm{cm}^{2}\right)\end{array}$ & $\begin{array}{c}S_{P t} \\
\left(\mathrm{~m}^{2} / \mathrm{g}\right)\end{array}$ & $\begin{array}{c}\text { Particle } \\
\text { size } \\
(\mathrm{nm})\end{array}$ & $\begin{array}{c}\text { Catalytic } \\
\text { activity } \\
\left(\mathrm{A} / \mathrm{g}_{\mathrm{Pt}}\right)\end{array}$ \\
\hline Procedure 1 & 1 & 5 & 1.8 & 12.7 & 22 & 8 \\
\hline Procedure 1 & 1 & 15 & 2.9 & 12.2 & 23 & 6 \\
\hline Procedure 2 & 5 & 1 & 3.3 & 10.5 & 27 & 14 \\
\hline Procedure 2 & 3 & 5 & 8.2 & 12.8 & 21 & 6 \\
\hline
\end{tabular}

Table 2. Amount of platinum deposited, platinum surface area, particle size and catalytic activity towards methanol oxidation obtained for $\mathrm{Pt} /$ macroporous carbon electrodes prepared in different PSD conditions. In all the cases the initial potential was $0.8 \mathrm{~V}$.

\begin{tabular}{|c|c|c|c|c|c|}
\hline $\begin{array}{c}\text { PSD } \\
\text { Method }\end{array}$ & Electrode & $\begin{array}{c}m_{P t} \\
\left(\mu \mathrm{g} / \mathrm{cm}^{2}\right)\end{array}$ & $\begin{array}{c}S_{P t} \\
\left(\mathrm{~m}^{2} / g\right)\end{array}$ & $\begin{array}{c}\text { Particle } \\
\text { size }(\mathrm{nm})\end{array}$ & $\begin{array}{c}\text { Catalytic } \\
\text { activity } \\
\left(A / g_{P t}\right)\end{array}$ \\
\hline Procedure 1 & $10 \mathrm{~s} 0 \mathrm{~V}$ & 11.4 & 10.5 & 27 & 25 \\
\hline Procedure 1 & $10 \mathrm{~s} 0.05 \mathrm{~V}$ & 9.9 & 21.7 & 13 & 55 \\
\hline Procedure 1 & $10 \mathrm{~s} 0.10 \mathrm{~V}$ & 7.3 & 23.9 & 12 & 44 \\
\hline Procedure 1 & $10 \mathrm{~s} 0.20 \mathrm{~V}$ & 4.7 & 9.5 & 29 & 12 \\
\hline Procedure 1 & $6 \mathrm{~s} 0.10 \mathrm{~V}$ & 2.7 & 11.0 & 25 & 13 \\
\hline Procedure 3 & $1 \mathrm{~s}-0.35 \mathrm{~V}+6 \mathrm{~s} 0.10 \mathrm{~V}$ & 11.5 & 17.9 & 16 & 41 \\
\hline Procedure 3 & $1 \mathrm{~s}-0.25 \mathrm{~V}+6 \mathrm{~s} 0.10 \mathrm{~V}$ & 9.4 & 19.4 & 14 & 39 \\
\hline Procedure 3 & $1 \mathrm{~s}-0.15 \mathrm{~V}+6 \mathrm{~s} 0.10 \mathrm{~V}$ & 5.7 & 21.4 & 13 & 64 \\
\hline Procedure 3 & $1 \mathrm{~s} 0 \mathrm{~V}+6 \mathrm{~s} 0.10 \mathrm{~V}$ & 5.4 & 19.3 & 14 & 46 \\
\hline Procedure 4 & $-0.15 \mathrm{~V} / 0.80 \mathrm{~V} 5 \mathrm{~ms}(5 \mathrm{~s})$ & 3.7 & 29.7 & 9 & 87 \\
\hline Procedure 4 & $0 \mathrm{~V} / 0.80 \mathrm{~V} 5 \mathrm{~ms}(5 \mathrm{~s})$ & 2.7 & 20.4 & 14 & 40 \\
\hline
\end{tabular}


Table 3. Amount of platinum deposited, platinum surface area, particle size and catalytic activity towards methanol oxidation obtained for Pt/polymer/Glassy carbon electrodes prepared in different PSD conditions. In all the cases the initial potential was $0.80 \mathrm{~V}$ and thickness of polymer film $130 \mathrm{~nm}$.

\begin{tabular}{|c|c|c|c|c|c|c|}
\hline Composite & $\begin{array}{c}P S D \\
\text { Method }\end{array}$ & Electrode & $\begin{array}{c}m_{P t} \\
\left(\mu \mathrm{g} / \mathrm{cm}^{2}\right)\end{array}$ & $\begin{array}{c}S_{P t} \\
\left(m^{2} / g\right)\end{array}$ & $\begin{array}{c}\text { Particle } \\
\text { size } \\
(\mathrm{nm})\end{array}$ & $\begin{array}{c}\text { Catalytic } \\
\text { activity } \\
\left(\mathrm{A} / \mathrm{g}_{P t}\right)\end{array}$ \\
\hline PANI/G.C. & Proc. 1 & $30 \mathrm{~s} 0.10 \mathrm{~V}$ & 19.6 & 16.3 & 17 & 30 \\
\hline PANI/G.C. & Proc. 3 & $1 \mathrm{~s}-0.25 \mathrm{~V} / 30 \mathrm{~s} 0.1 \mathrm{~V}$ & 18.6 & 17.1 & 16 & 31 \\
\hline PANI/G.C. & Proc. 3 & $1 \mathrm{~s}-0.15 \mathrm{~V} / 30 \mathrm{~s} 0.1 \mathrm{~V}$ & 12.6 & 17.3 & 16 & 30 \\
\hline PANI/G.C. & Proc. 3 & $1 \mathrm{~s}-0.25 \mathrm{~V} / 6 \mathrm{~s} 0.1 \mathrm{~V}$ & 3.6 & 16.1 & 17 & 29 \\
\hline PANI/G.C. & Proc. 3 & $1 \mathrm{~s}-0.15 \mathrm{~V} / 6 \mathrm{~s} 0.1 \mathrm{~V}$ & 3.7 & 17.7 & 16 & 30 \\
\hline POAP/G.C. & Proc. 1 & $30 \mathrm{~s} 0.05 \mathrm{~V}$ & 9.7 & 16.1 & 17 & 24 \\
\hline POAP/G.C. & Proc. 3 & $1 \mathrm{~s}-0.25 \mathrm{~V} / 30 \mathrm{~s} 0.1 \mathrm{~V}$ & 23.8 & 14.9 & 19 & 35 \\
\hline POAP/G.C. & Proc. 3 & $1 \mathrm{~s}-0.15 \mathrm{~V} / 30 \mathrm{~s} 0.1 \mathrm{~V}$ & 23.5 & 14.7 & 19 & 36 \\
\hline POAP/G.C. & Proc. 3 & $1 \mathrm{~s}-0.25 \mathrm{~V} / 6 \mathrm{~s} 0.1 \mathrm{~V}$ & 3.3 & 15.3 & 18 & 19 \\
\hline
\end{tabular}

Table 4. Amount of platinum deposited, platinum surface area, particle size and catalytic activity towards methanol oxidation for the three Pt/carbon electrodes prepared by PSD of multiple pulses (Procedure 4), $5 \mathrm{~ms}$ from $0.80 \mathrm{~V}$ to $-0.15 \mathrm{~V}(5 \mathrm{~ms})$, final time of $5 \mathrm{~s}$, in $0.1 \mathrm{M} \mathrm{MeOH}+0.5 \mathrm{M} \mathrm{H}_{2} \mathrm{SO}_{4}$ aqueous solution with a scan rate of 10 $\mathrm{mV} \cdot \mathrm{s}^{-1}$.

\begin{tabular}{|c|c|c|c|c|}
\hline Electrode & $\begin{array}{c}m_{P t} \\
\left(\mu \mathrm{g} / \mathrm{cm}^{2}\right)\end{array}$ & $\begin{array}{c}S_{P t} \\
\left(\mathrm{~m}^{2} / \mathrm{g}\right)\end{array}$ & $\begin{array}{c}\text { Particle size } \\
(\mathrm{nm})\end{array}$ & $\begin{array}{c}\text { Catalytic activity } \\
\left(\mathrm{A} / \mathrm{g}_{P t}\right)\end{array}$ \\
\hline Macroporous disc & 3.7 & 29.7 & 9.4 & 87 \\
\hline Glassy carbon & 10.6 & 12.6 & 22.3 & 56 \\
\hline Graphite & 4.1 & 15.3 & 18.4 & 49 \\
\hline
\end{tabular}


Table 5. Amount of platinum deposited, platinum surface area, particle size and catalytic activity towards methanol oxidation for the three Pt/carbon electrodes prepared by PSD of multiple pulses (Procedure 4), $5 \mathrm{~ms}$ from $0.80 \mathrm{~V}$ to $-0.15 \mathrm{~V}$ (final time of 5 s) in the case of macroporous carbon and double pulse from $0.8 \mathrm{~V}$ to $-0.15 \mathrm{~V}(1 \mathrm{~s})$ and $-0.15 \mathrm{~V}$ to $0.10 \mathrm{~V}(6 \mathrm{~s})$ for graphite and glassy carbon, $0.8 \mathrm{~V}$ to $0 \mathrm{~V}(1 \mathrm{~s})$ and $0 \mathrm{~V}$ to 0,10 $\mathrm{V}(30 \mathrm{~s})$ for PANI $0.8 \mathrm{~V}$ to $-0.15 \mathrm{~V}(1 \mathrm{~s})$ and $-0.15 \mathrm{~V}$ to $0.10 \mathrm{~V}(30 \mathrm{~s})$ for POAP in $0.1 \mathrm{M} \mathrm{MeOH}+0.5 \mathrm{M} \mathrm{H}_{2} \mathrm{SO}_{4}$ aqueous solution with a scan rate of $10 \mathrm{mV} \cdot \mathrm{s}^{-1}$.

\begin{tabular}{|c|c|c|c|c|}
\hline Electrode & $m_{P t}\left(\mu \mathrm{g} / \mathrm{cm}^{2}\right)$ & $S_{P t}\left(\mathrm{~m}^{2} / \mathrm{g}\right)$ & $\begin{array}{c}\text { Particle } \\
\text { size }(\mathrm{nm})\end{array}$ & $\begin{array}{c}\text { Catalytic } \\
\text { activity }\left(A / \mathrm{g}_{P t}\right)\end{array}$ \\
\hline Macroporous disc & 3.7 & 29.7 & 9.4 & 87 \\
\hline Glassy carbon & 5.0 & 22.6 & 12.4 & 68 \\
\hline Graphite & 4.1 & 20.5 & 13.7 & 49 \\
\hline PANI & 12.1 & 14.5 & 19.3 & 36 \\
\hline POAP & 23.5 & 14.7 & 19.2 & 36 \\
\hline
\end{tabular}




\section{FIGURE CAPTIONS}

Figure 1. Current versus time transient plot obtained during: a) Potential Step Deposition of a single step (Procedure 1) with samples of macroporous carbon changing the final potential; b) Potential Step Deposition of a double step (Procedure 3) with samples of glassy carbon changing the first potential; and c) a Potential Step Deposition of multiple steps (Procedure 4) with samples of glassy carbon changing the final potential of the steps.

Figure 2. Plots of the experimental data and the theoretical models of the platinum deposition on a sample of a macroporous carbon under the following conditions of Potential Step Deposition: one step from an initial potential of $0.80 \mathrm{~V}$ to a final potential of $0.05 \mathrm{~V}$ during $15 \mathrm{~s}$, corresponding to (a) 2D and (b) 3D models.

Figure 3. Plots of the experimental data and the theoretical models for $3 \mathrm{D}$ nucleation of the platinum deposition on (O) PANI and ( ) POAP under the following conditions of Potential Step Deposition: one step from an initial potential of $0.80 \mathrm{~V}$ to a final potential of $0.05 \mathrm{~V}$ during $60 \mathrm{~s}$ and thickness of polymer film $400 \mathrm{~nm}$.

Figure 4. XPS spectrum in the Pt 4f region of macroporous carbon with Pt deposited by PSD in 3 steps of $5 \mathrm{~s}$ from $0.80 \mathrm{~V}$ to $0.15 \mathrm{~V}$ (Procedure 2).

Figure 5. The cyclic voltammograms of $\mathrm{Pt} /$ glassy carbon electrodes at $50 \mathrm{mV} \cdot \mathrm{s}^{-1}$, in $0.5 \mathrm{M} \mathrm{H}_{2} \mathrm{SO}_{4}$ aqueous solution, before and after a Potential Step Deposition. 
Figure 6. SEM micrographs and their respective histogram (corresponding to the particle size distributions based on a 100-particle count) of Pt deposited by PSD according to procedure 3 (from $0.80 \mathrm{~V}$ to an intermediate potential of $-0.15 \mathrm{~V}$ (1s) and immediately to $0.10 \mathrm{~V}$ for $6 \mathrm{~s}$ ) on (a) glassy carbon, on (b) macroporous carbon and on (c) graphite.

Figure 7. TEM images of Pt deposited by PSD according to procedure 3 (from $0.80 \mathrm{~V}$ to an intermediate potential of $-0.25 \mathrm{~V}$ for $1 \mathrm{~s}$, and immediately to $0.10 \mathrm{~V}$ for $6 \mathrm{~s}$ ) on the macroporous carbon.

Figure 8. Cyclic voltammograms for the best Pt/carbon and Pt/conducting polymer electrodes obtained at $10 \mathrm{mV} \cdot \mathrm{s}^{-1}$, in $0.1 \mathrm{M} \mathrm{MeOH}+0.5 \mathrm{M} \mathrm{H}_{2} \mathrm{SO}_{4}$ solution.

Figure 9. Relationship between particle size and catalytic activity in methanol oxidation on a) (ם) Pt/macroporous carbon, (o) Pt/graphite and ( ) Pt/glassy carbon electrodes and b) $(\Delta) \mathrm{Pt} / \mathrm{PANI}$ and $(\nabla) \mathrm{Pt} / \mathrm{POAP}$.

Figure 10. Impedance spectra during methanol oxidation $(0.8 \mathrm{~V})$ in $0.1 \mathrm{M} \mathrm{CH}_{3} \mathrm{OH}$ $+0.5 \mathrm{M} \mathrm{H}_{2} \mathrm{SO}_{4}$, for different electrodes. 


\section{FIGURES}

Figure 1

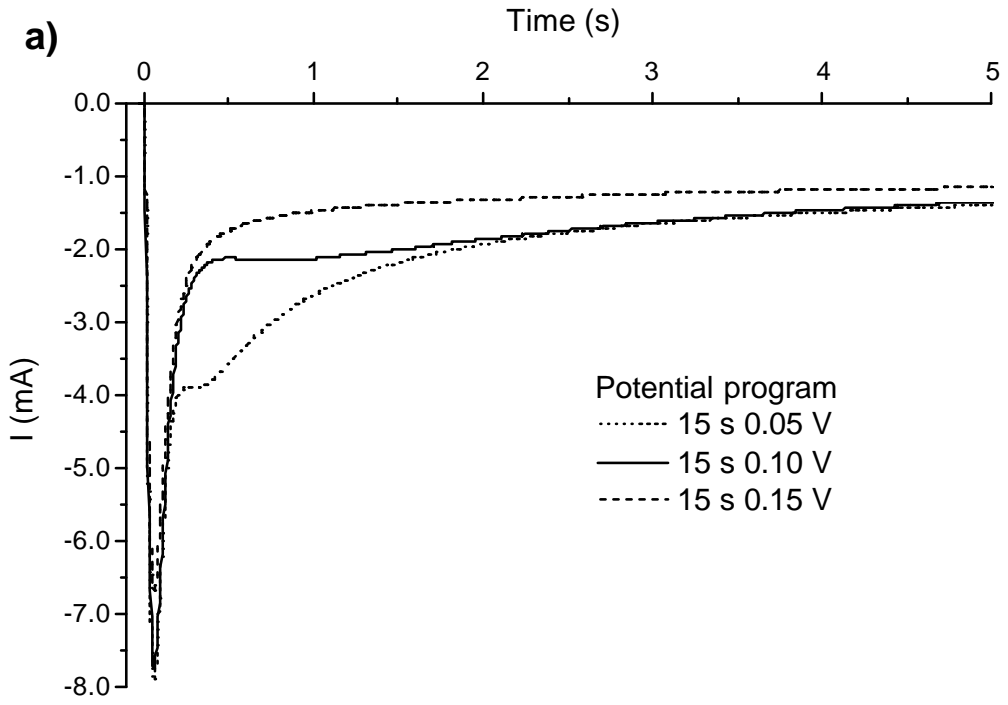

b)
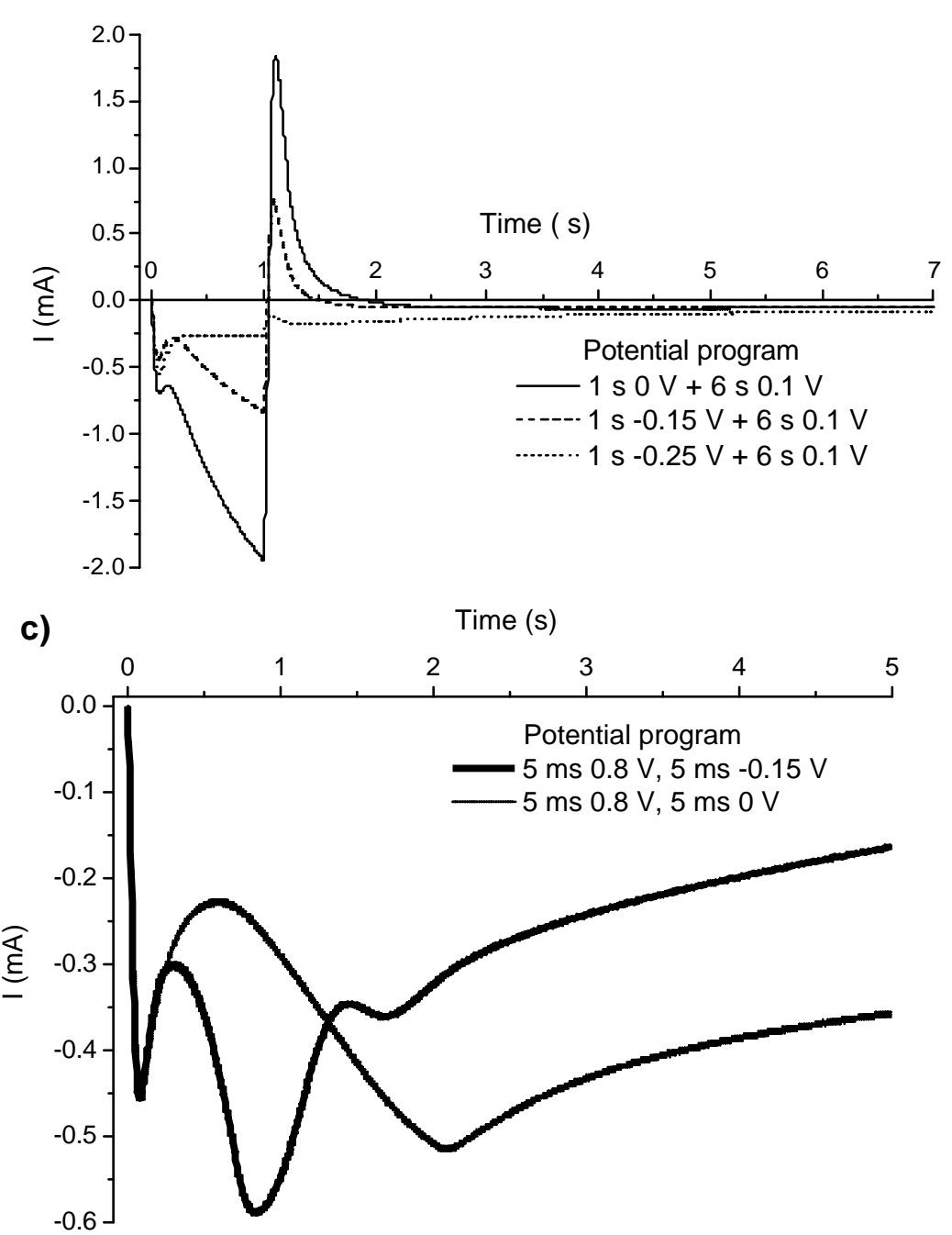


\section{Figure 2}

a)

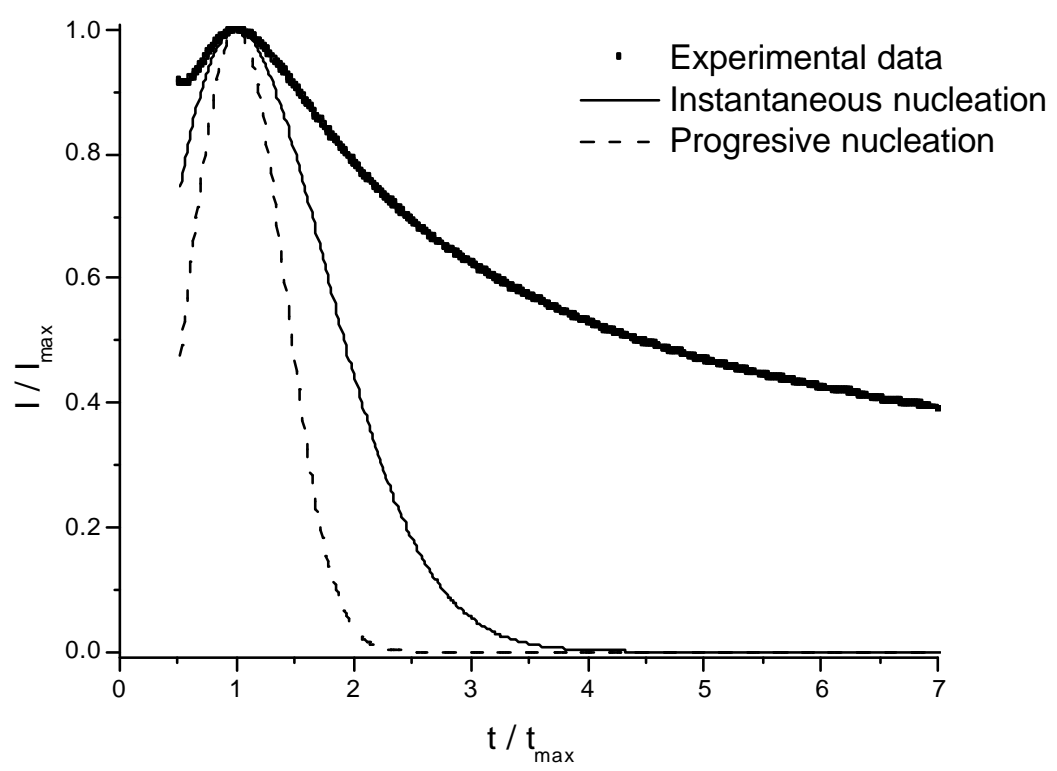

b)

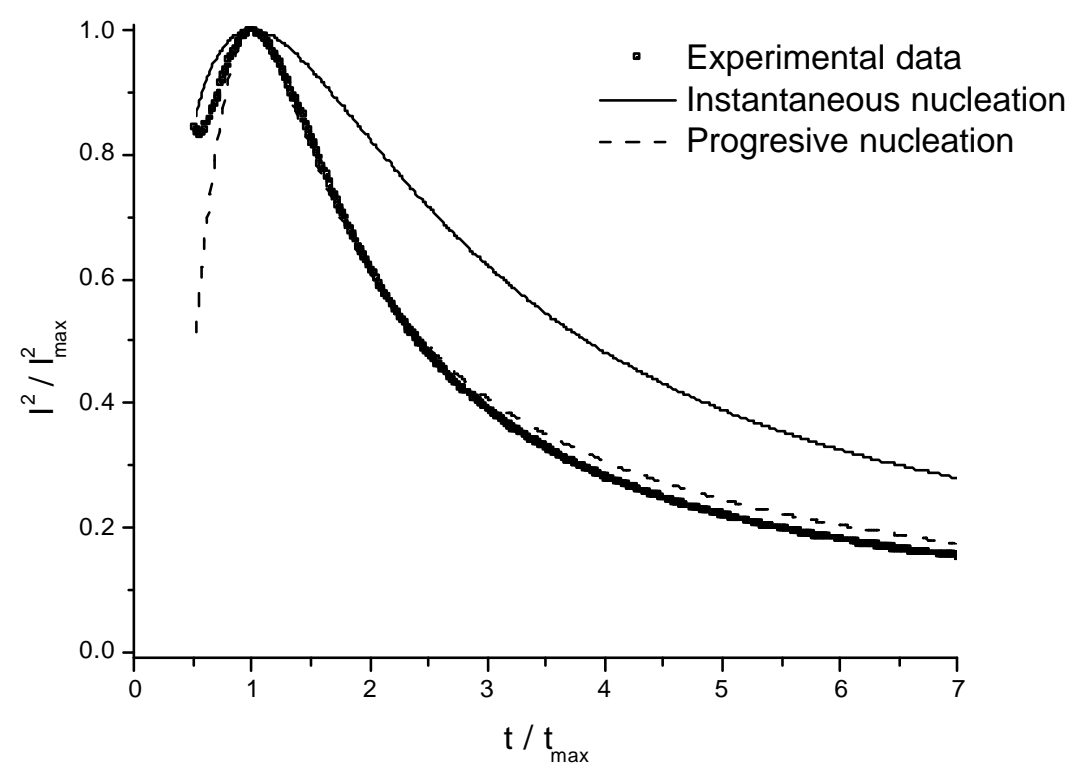




\section{Figure 3}

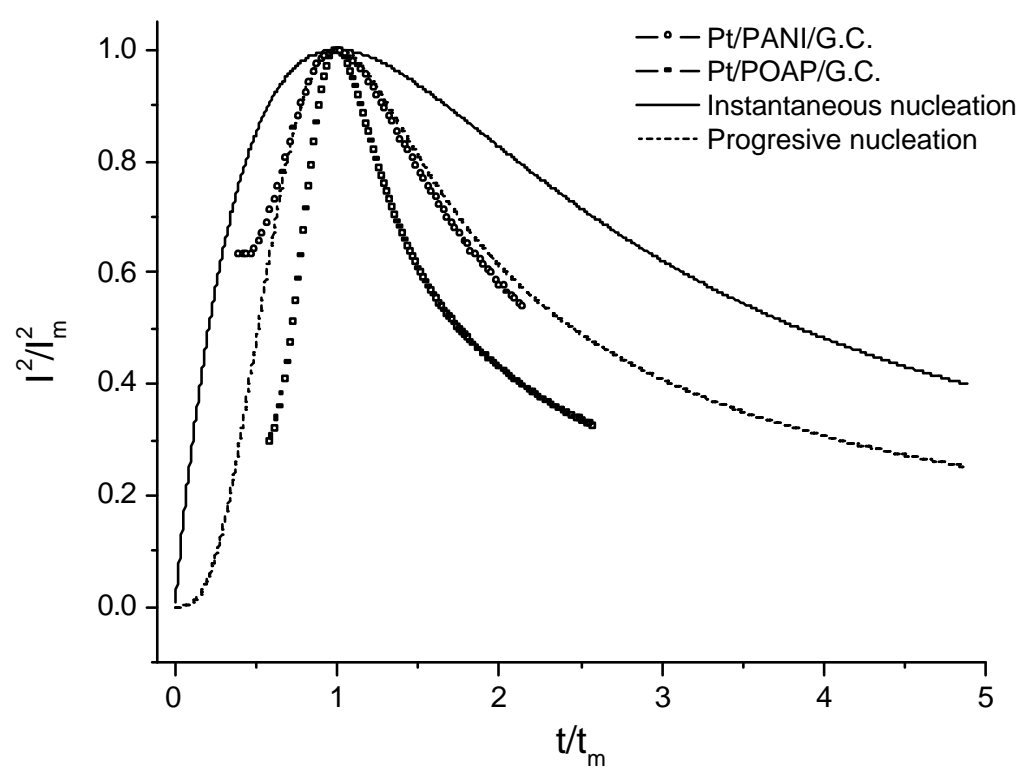




\section{Figure 4}

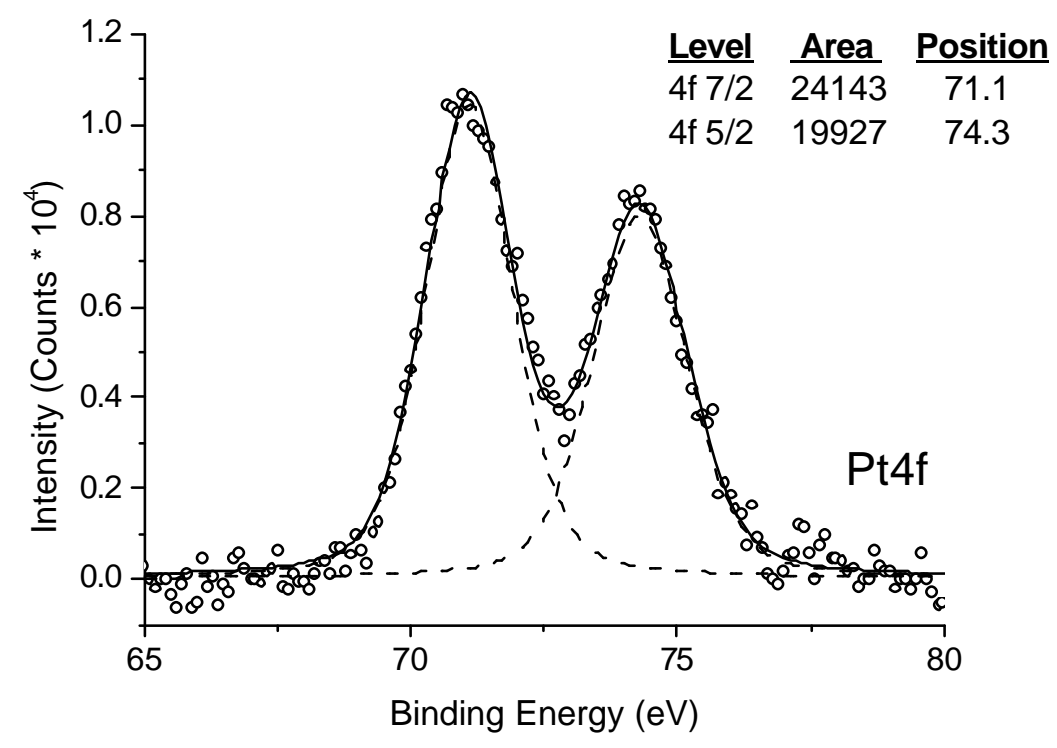




\section{Figure 5}

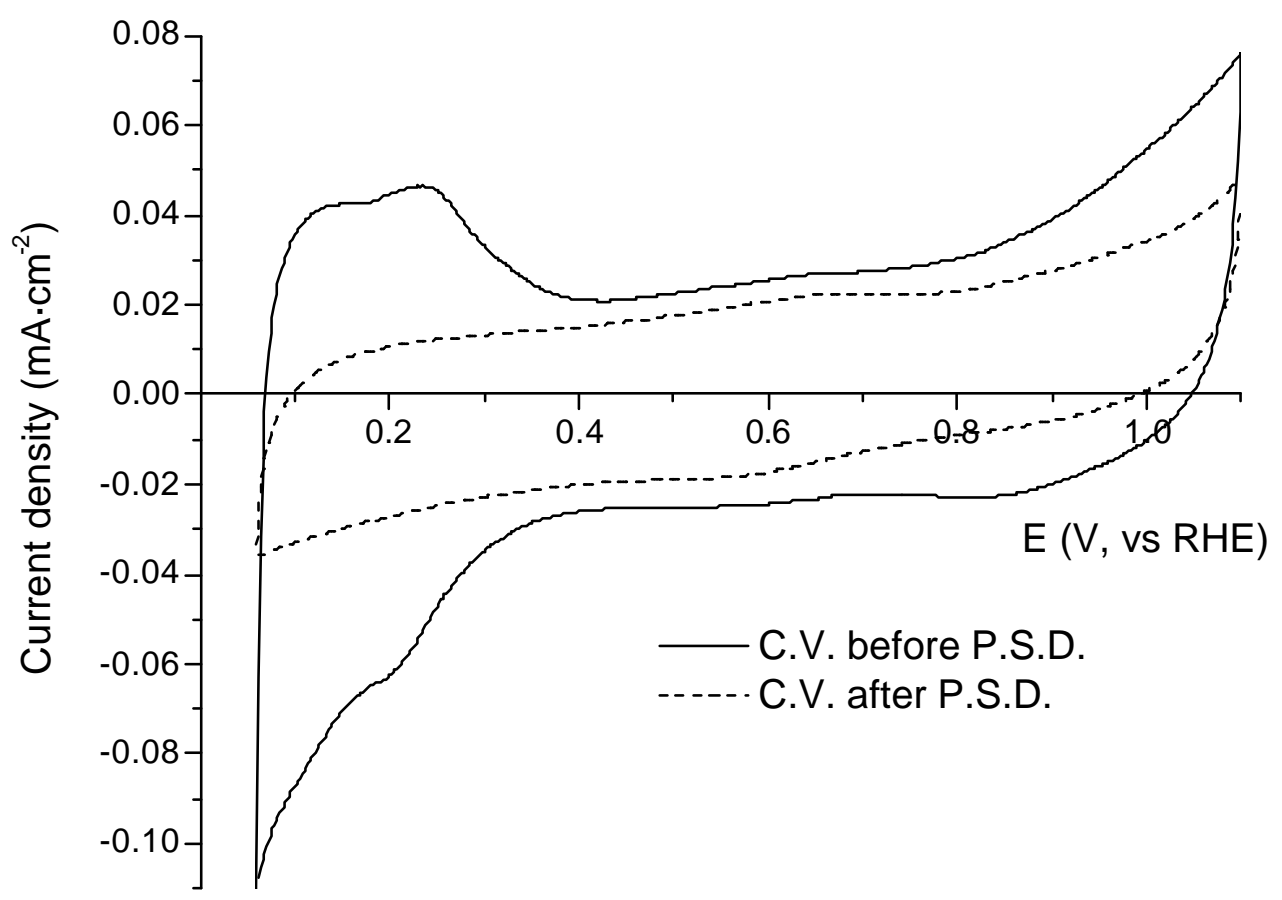




\section{Figure 6}
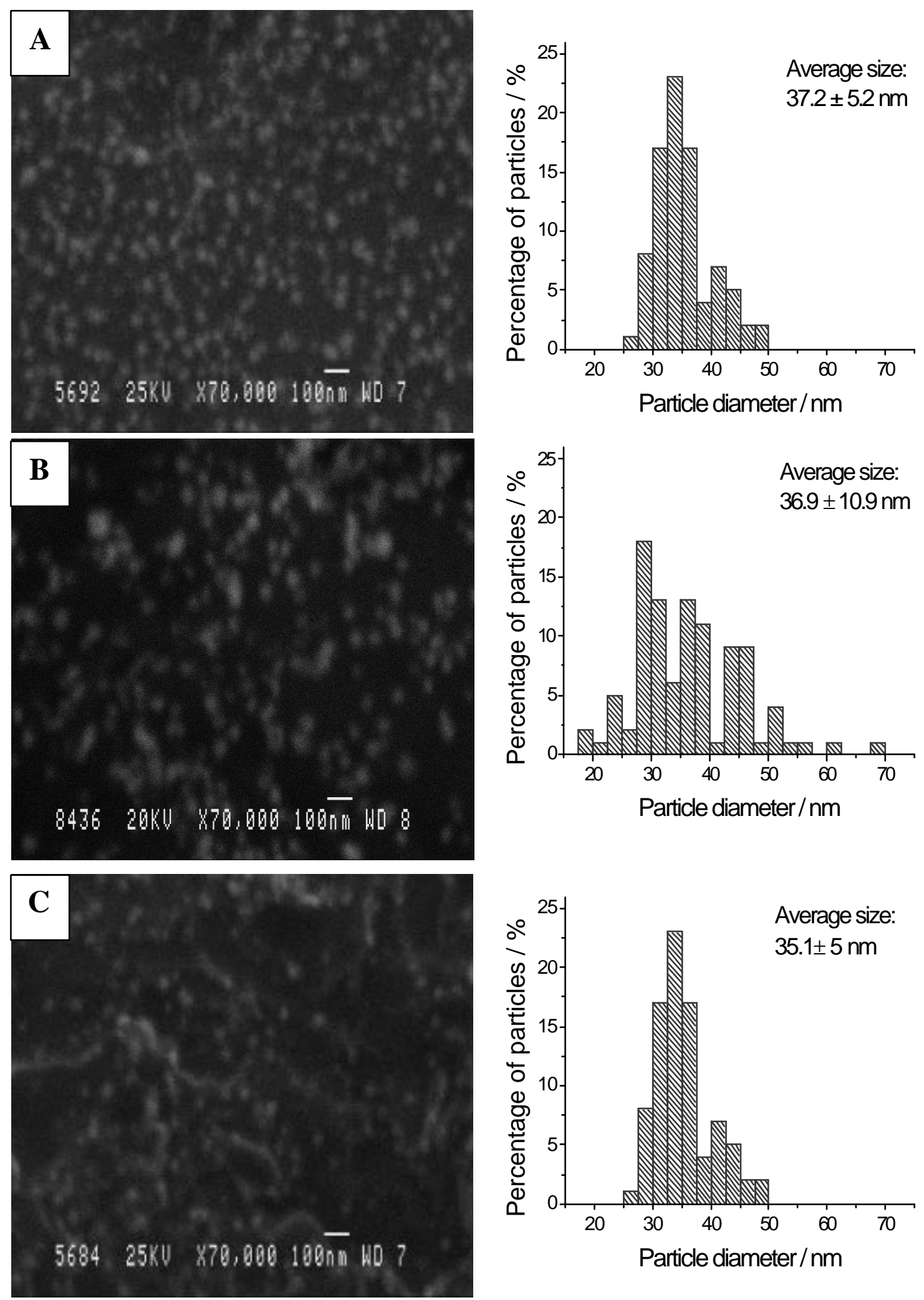
Figure 7
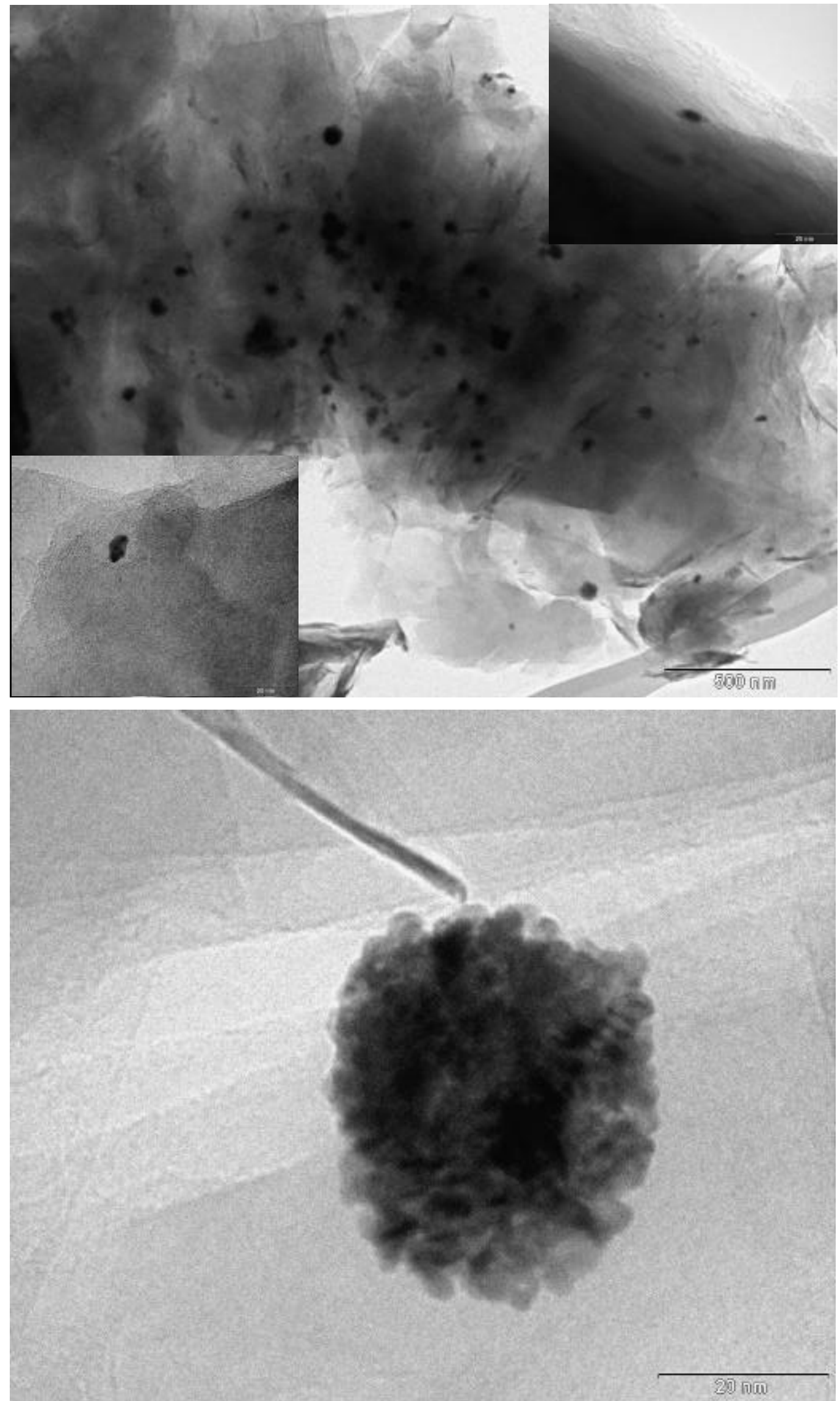


\section{Figure 8}
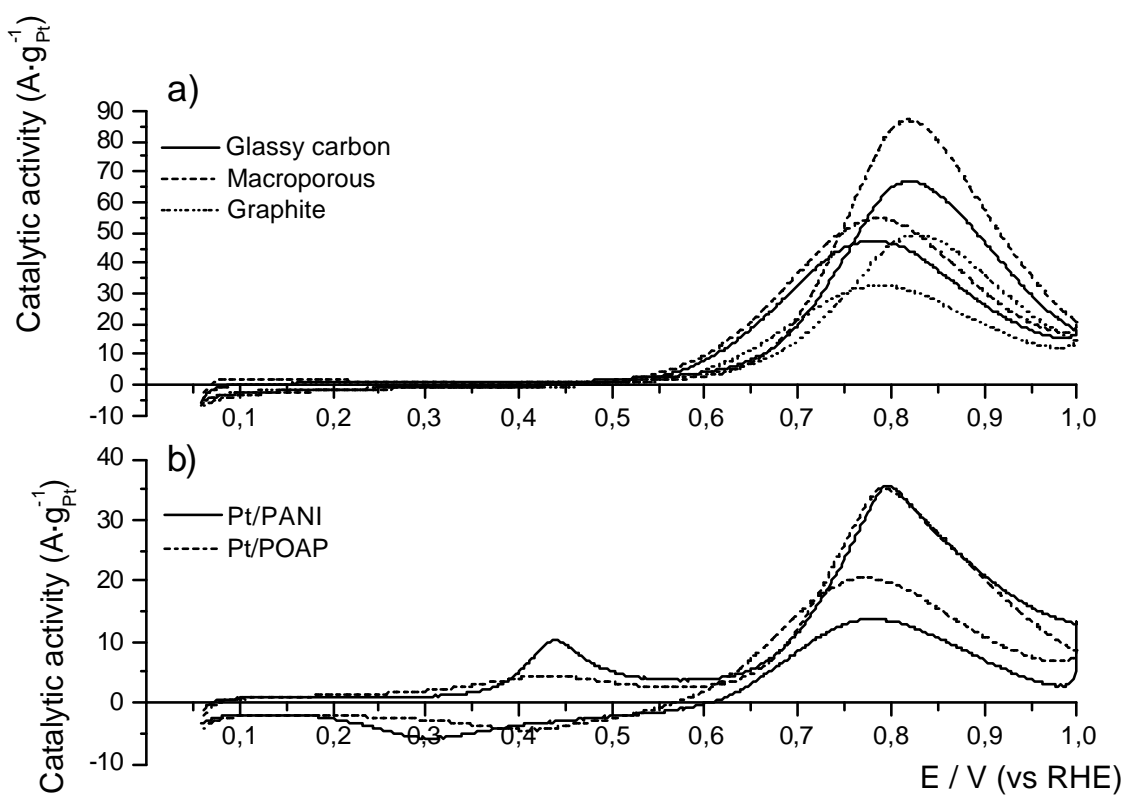
Figure 9

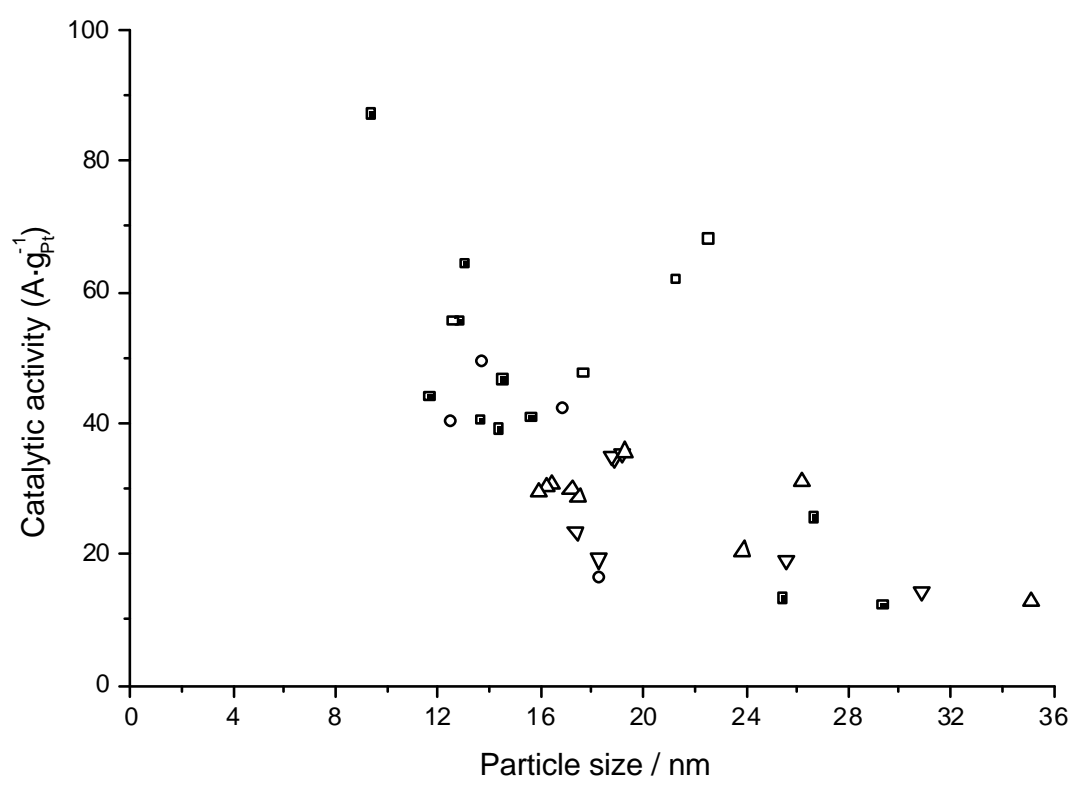


Figure 10

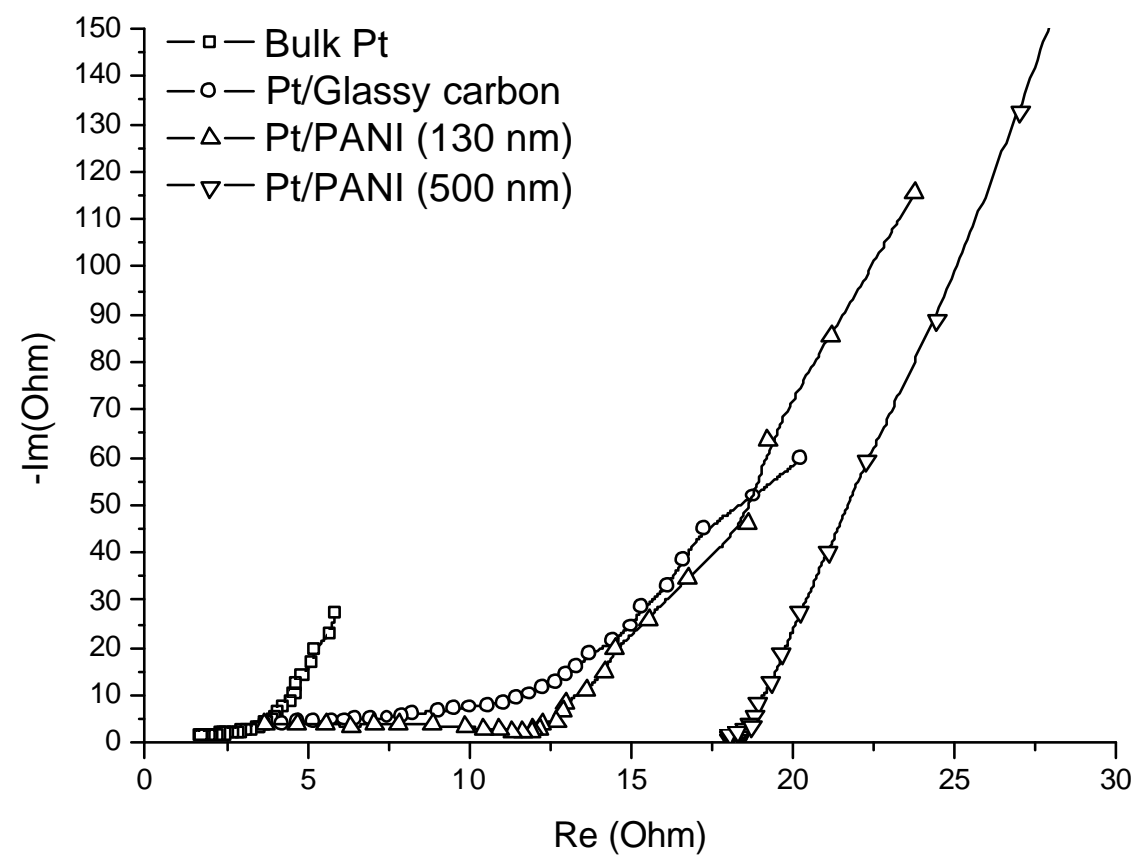




\section{REFERENCES}

[1] Lordi V, Yao N, Wei J (2001) Chem. Mater. 13:733.

[2] Endo M, Kim YA, Ezaka M, Osada K, Yanagiswa T, Hayashi T, Terrones M, Dresselhaus MS (2003) Nano Lett. 3:723.

[3] Boxall DL, Deluga GA, Kenik EA, King WD, Lukehart CM (2001) Chem. Mater. 13:891.

[4] Solla-Gullón J, Montiel V, Aldaz A, Clavilier J (2000) J. Electroanal. Chem. 491:69.

[5] Liu ZL, Lee JY, Han M, Chen WX, Gan LM (2002) J. Mater. Chem. 12:2453.

[6] Li WZ, Liang CH, Zhou WJ, Qiu JS, Zhou ZH, Sun GQ, Xin Q (2003) J. Phys. Chem. 107:6292.

[7] Yu G, Chen W, Zhao J, Nie Q (2006) J. Appl. Electrochem. 36:1021.

[8] Chen WX, Zhao J, Lee JY, Liu ZL (2005) Mater. Chem. Phys. 91:124.

[9] Xue XH, Lu TH, Liu CP, Xing W (2005) Chem. Commun. 12:1601.

[10] He P, Liu H, Li Z, Li J (2005) J. Electrochem. Soc. 152:E146.

[11] Tang H, Chen J, Nie L, Liu D, Deng W, Kuang Y, Yao S (2004) J. Colloid Interface Sci. 269:26.

[12] Plyasova LM, Molina IY, Gavrilov AN, Cherepanova SV, Cherstiouk OV, Rudina NA, Sadinova ER, Tsirlina GA (2006) Electrochim. Acta 54:4477.

[13] Ye J, Cui H, Wen Y, Zhang W, Xu G, Sheu F (2006) Microchim. Acta $152: 267$.

[14] Tang H, Chen J, Yao S, Nie L, Kuang Y, Huang Z, Wang D, Ren Z (2005) Mater. Chem. Phys. 92:548.

[15] He Z, Chen J, Liu D, Tang H, Deng W, Kuang Y (2004) Mater. Chem. Phys. $85: 396$.

[16] Duarte MME, Pilla AS, Sieben JM, Mayer CE (2006) Electrochem. Commun. 8:159.

[17] Ueda M, Dietz H, Anders A, Kneppe H, Meixner A, Plieth W (2002) Electrochim. Acta 48:377.

[18] Zoval JV, Lee J, Gorer S, Penner RM (1998) J. Phys. Chem. B 102:1166. 
[19] Burchell TD (1999) in Carbon Materials for Advances Technologies, Pergamon, New York.

[20] Marsh H, Rodriguez-Reinoso F (1997) in Sciences of Carbon Materials, Publicaciones de la Universidad de Alicante, Alicante.

[21] Kinoshita K (1998) in Carbon, Electrochemical and Physicochemical Properties, Wiley, New York.

[22] Montilla F, Morallón E, Vázquez JL, Alcañiz-Monge J, Cazorla-Amorós D, Linares-Solano A (2002) Carbon 40:2193.

[23] Berenguer-Murcia A, Morallón E, Cazorla-Amorós D, Linares-Solano A (2005) Micropor. Mesopor. Mater. 78:159.

[24] Montilla F, Morallón E, Duo I, Comninellis C, Vázquez JL (2003) Electrochim. Acta 48:3891.

[25] Malinauskas A (1999) Synth. Met. 107:75.

[26] Podlovchenko BI, Andreev VN (2002) Russ. Chem. Rev. 71:837.

[27] J. Arias-Pardilla (2007) PhD Thesis, University of Alicante.

[28] Paunovic M, Schlesinger M (1998) in Fundamentals of Electrochemical Deposition, Wiley Interscience, New York,.

[29] Scharifker B, Hills G (1983) Electrochim. Acta 28:879.

[30] Bade K, Tsakova V, Schultze JW (1992) Electrochim. Acta 37:2255.

[31] Gloaguen F, Léger JM, Lamy C, Marmann A, Stimming U, Vogel R (1999) Electrochim. Acta 44:1805.

[32] Hernández N, Ortega JM, Coi M, Ortiz R (2001) J. Electroanal. Chem. $515: 123$

[33] Tang YW, Zhang LL, Wang YN, Zhou YM, Gao Y, Liu CP, Xing W, Lu TH (2006) J. Power Sources 162:124.

[34] Gènies L, Faure R, Durand R (1998) Electrochim. Acta 44:1317.

[35] Kim SS, Nah YC, Noh YY, Jo J, Kim DY (2006) Electrochim. Acta 51:3814.

[36] Wang HJ, Yu H, Peng F, Lv P (2006) Electrochem. Commun. 8:499.

[37] Frelink T, Visscher W, van Veen JAR (1995) J. Electroanal. Chem. 382:65.

[38] Bergamaski K, Pinheiro ALN, Teixeira-Neto E, Nart FC (2006) J. Phys. Chem. B 110:19271.

[39] Kim S, Park SJ (2006) J. Power Sources 159:42. 